\title{
Asexual reproduction strategies and blooming potential in Scyphozoa
}

\author{
Agustín Schiariti ${ }^{1,2, *}$, André C. Morandini ${ }^{3}$, Gerhard Jarms ${ }^{4}$, Renato von Glehn Paes ${ }^{3}$, \\ Sebastian Franke ${ }^{4}$, Hermes Mianzan ${ }^{1,2}$
}

${ }^{1}$ Instituto Nacional de Investigación y Desarrollo Pesquero (INIDEP), Paseo V, Ocampo No. 1, B7602HSA Mar del Plata, Argentina ${ }^{2}$ Instituto de Investigaciones Marinas y Costeras (IIMYC), CONICET, Universidad Nacional de Mar del Plata, 7600 Argentina

${ }^{3}$ Departamento de Zoologia, Instituto de Biociências, Universidade de São Paulo (USP), Rua do Matão trav. 14 n. 101 , São Paulo, 05508-090 SP, Brazil

${ }^{4}$ Biocenter Grindel and Zoological Museum, University of Hamburg, Martin-Luther-King Platz 3, 20146 Hamburg, Germany

\begin{abstract}
Scyphistomae show different modes of propagation, occasionally allowing the sudden release of great numbers of medusae through strobilation leading to so-called jellyfish blooms. Accordingly, factors regulating asexual reproduction strategies will control scyphistoma density, which, in turn, may influence blooming potential. We studied 11 scyphistoma species in 6 combinations of temperature and food supply to test the effects of these factors on asexual reproduction strategies and reproduction rates. Temperature and food availability increased reproduction rates for all species and observed reproduction modes. In all cases, starvation was the most important factor constraining the asexual reproduction of scyphistomae. Differences in scyphistoma density were found according to the reproductive strategy adopted by each species. Different Aurelia lineages and Sanderia malayensis presented a multi-mode strategy, developing up to 5 propagation modes. These species reached the highest densities, mostly through lateral budding and stolons. Cassiopea sp., Cephea cephea, Mastigias papua and Phyllorhiza punctata adopted a mono-mode reproductive strategy, developing only free-swimming buds. Lychnorhiza lucerna, Rhizostoma pulmo and Rhopilema esculentum also presented a mono-mode strategy, but they only developed podocysts. These 3 species had the lowest reproduction rates and polyp densities; not only their reproduction rates but also the need for a 2 -fold set of environmental stimuli to produce new polyps (one for encystment, another for excystment) made this reproduction mode the slowest of those observed to be utilized for propagation. We conclude that blooms may be defined phylogenetically by the specific asexual modes each species develops, which, in turn, is regulated by environmental conditions.
\end{abstract}

KEY WORDS: Polyp $\cdot$ Scyphistomae $\cdot$ Mono-mode strategy $\cdot$ Multi-mode strategy $\cdot$ Budding Podocysts

\section{INTRODUCTION}

A main feature of the majority of blooming scyphozoans is the presence of a benthic polyp stage during which several asexual reproduction modes are utilized for propagation. In turn, under specific environmental conditions polyps produce and release great numbers of ephyrae (through strobilation), leading to population pulses that can sometimes result in medusa outbreaks or the socalled jellyfish blooms (CIESM 2001). Accordingly, it is logical to assume that once strobilation is triggered, the greater the number of scyphistomae, the higher the number of released medusae. Therefore, factors regulating polyp density will influence the formation of medusae blooms. 
Different environmental factors have been proposed to influence scyphistoma asexual reproduction and mortality rates. Among them, temperature and food availability appear to be the most important ones for the majority of species (Lucas et al. 2012). In general, reproduction rates increase with temperature and food supply. However, the results available in the literature are conflicting and have hindered our understanding of reproductive patterns, as made evident in the review by Lucas et al. (2012).

One of the reasons behind these controversial results may be found in the diversity of asexual reproductive strategies existing among scyphozoans and their interactions with multiple environmental factors. Only a handful of studies have discriminated between the different asexual modes scyphistomae exhibit during propagation (e.g. Han \& Uye 2010), with the majority of studies focusing on the formation of podocysts and 'buds'. However, non-coronate scyphozoans multiply through a variety of asexual reproduction modes (Adler \& Jarms 2009). Although the final product of these propagation modes is in all cases a new polyp, the use of a particular mode, or a combination of more than one mode, might have ecological implications related to blooming potential.

While some species exhibit the potential to display several asexual modes, even simultaneously, others only exhibit a few or just one (Adler \& Jarms 2009). Therefore, considering the reproductive strategy to be the number and type of asexual reproduction modes displayed and the relative importance of each mode to polyp density, we hypothesize that those species capable of switching their reproductive strategy in response to environmental fluctuations will have a greater blooming potential. Although differ- ent asexual reproduction modes have been described for several species, little is known about the importance of each of them in terms of polyp propagation. To address these questions we performed a series of experiments involving 11 scyphistoma species. These experiments were organized to evaluate the effect of different combinations of temperature and food supply on the asexual reproductive strategy of each species. The null hypotheses tested were that reproductive strategy, reproduction rates and polyp density did not differ according to species or experimental conditions.

\section{MATERIALS AND METHODS}

Scyphistomae were reared in laboratory cultures from specimens collected in their natural environment or obtained from artificial fertilization. All species were maintained inside incubators under the temperatures and salinities provided in Table 1. Scyphistomae were kept in the dark and fed once weekly with newly hatched Artemia nauplii. Cultures were maintained in glass or polystyrene dishes ( $200 \mathrm{ml}$ ) filled with filtered (5 $\mu \mathrm{m})$ seawater (34 psu). Although Cassiopea sp., Cephea cephea, Mastigias papua and Phyllorhiza punctata polyps usually host zooxanthellae in their tissues (which are important for strobilation), no studies have indicated that darkness influences other types of asexual reproduction (except for that of Cassiopea andromeda; Hofmann et al. 1978).

Combined effects of temperature and food supply were observed separately for 11 scyphozoan species. The experiments included 3 different temperatures

Table 1. List of species, and culture and experimental conditions used in the present study. T2: culture conditions prior to the experiment; T1 and T3: T2 $-5^{\circ} \mathrm{C}$ and T2 $+5^{\circ} \mathrm{C}$, respectively. HL: Helgoland; JP: Japan; FR: France

\begin{tabular}{|c|c|c|c|c|c|}
\hline \multirow[t]{2}{*}{ Species } & \multirow[t]{2}{*}{ Track culture/origin } & \multicolumn{2}{|c|}{ Culture conditions } & \multicolumn{2}{|c|}{ Experimental conditions } \\
\hline & & $\begin{array}{l}\text { Temp. } \\
\left({ }^{\circ} \mathrm{C}\right)\end{array}$ & Salinity & $\begin{array}{l}\text { Temp. }\left({ }^{\circ} \mathrm{C}\right): \\
\mathrm{T} 1, \mathrm{~T} 2, \mathrm{~T} 3\end{array}$ & Salinity \\
\hline Aurelia sp.HL & Helgoland, Germany & 10 & 34 & $5,10,15$ & 34 \\
\hline Aurelia sp.JP & Kagoshima Bay, Japan & 20 & 34 & $15,20,25$ & 34 \\
\hline Aurelia sp.FR & Roskoff, France & 20 & 34 & $15,20,25$ & 34 \\
\hline Sanderia malayensis & Same as in Adler \& Jarms (2009) & 20 & 34 & $15,20,25$ & 34 \\
\hline Cassiopea sp. & Cabo Frio, Brazil & 20 & 34 & $15,20,25$ & 34 \\
\hline Cephea cephea & Berlin Zoo Aquarium & 20 & 34 & $15,20,25$ & 34 \\
\hline Mastigias papua & Berlin Zoo Aquarium & 20 & 34 & $15,20,25$ & 34 \\
\hline Phyllorhiza punctata & Berlin Zoo Aquarium & 20 & 34 & $15,20,25$ & 34 \\
\hline Lychnorhiza lucerna & San Clemente del Tuyú, Argentina & 20 & 22 & $15,20,25$ & 22 \\
\hline Rhizostoma pulmo & Mar Menor, Spain & 15 & 34 & $10,15,20$ & 34 \\
\hline Rhopilema esculentum & Kamo Aquarium, Japan & 15 & 34 & $10,15,20$ & 34 \\
\hline
\end{tabular}


(maintained by incubators; Table 1) and 2 feeding conditions (starvation, feeding ad libitum). Fully developed scyphistomae showing no external evidence of reproduction were detached from the stem cultures and placed in experimental units (glass dishes containing $150 \mathrm{ml}$ of filtered seawater). Scyphistomae were allowed to reattach and acclimate to the experimental temperatures for $1 \mathrm{wk}$ without food. Dishes were covered by glass plates to avoid evaporation. They were held in the dark, except during observation periods ( 30 min observation $\left.{ }^{-1}\right)$ and water exchange. Each experimental unit included 1 individual scyphistoma. Three replicates were utilized for each combination of temperature and food supply, accounting for a total of 18 initial polyps per species. Experimental temperatures were chosen based on species culture conditions (Table 1). Scyphistomae were fed twice weekly with newly hatched Artemia nauplii. After the scyphistomae fed for $2 \mathrm{~h}$, seawater, debris and uneaten food were discarded and replaced with filtered seawater at the corresponding temperature and salinity conditions. The presence of uneaten food items in all cases after the feeding period guaranteed that ad libitum conditions had been provided.

Prior to each feeding event, the following variables were registered: (1) specific asexual reproduction modes, (2) the number of polyps produced during the 6 wk experimental period, i.e. polyp density (PD), (3) the total number of reproductive products produced during the 6 wk experimental period, i.e. overall reproduction rates $(\mathrm{Rr})$ and (4) the number of each type of reproductive product produced during the $6 \mathrm{wk}$ experimental period, i.e. specific reproduction rates. The different asexual reproduction modes were identified according to Adler \& Jarms (2009). All reproductive products unable to feed (motile or non-motile, attached to or detached from the mother polyp) were considered for Variables 3 and 4. Once tentacles had developed and feeding had started, they were considered new individuals and considered in PD measurements.

Null hypotheses were examined by 2-way ANOVA or Kruskal-Wallis tests depending on whether each data set met the assumptions of normality and homocedasticity. In case of significant differences either Bonferroni's or Dunn's post hoc test was performed. In some cases of very low or null reproduction, or mortality of scyphistomae, we chose not to test the data for the 2 stud- ied factors because interaction could not be determined due to missing data (no polyps or no reproductive products). In these cases, we used a $t$-test, 1-way ANOVA, or the non-parametric Mann-Whitney and Kruskal-Wallis tests depending on whether or not each data set met the assumptions.

\section{RESULTS}

\section{Asexual reproduction modes}

We observed the following asexual reproduction modes: typical lateral budding (LB), lateral budding by means of stolons (LBst), 'Sanderia-type' budding (StyB), reproduction from parts of stolons/stalks (ST), typical free-swimming buds/planuloids (FSB), motile bud-like tissue particles (MP) and podocysts (POD) (Table 2, Fig. 1).

Three different asexual reproduction modes involved the formation of stolons. In the LBst, a bud emerges from a stolon giving place to a new polyp (Fig. 1B) (see description in Adler \& Jarms 2009). On the other hand, once a stolon is formed, this new stolon (or the old stalk) is constricted and severed, leaving variable amounts of tissue attached near the mother polyp from where new scyphistomae develop. These tissue fragments were registered as reproductive products and designated ST (Fig. 1D). Finally, formation of PODs occurred beneath the

Table 2. Observed asexual reproduction modes for the studied species (for details on the reproductive modes see the 'Results' section). LB: typical lateral budding; LBst: lateral budding by means of stolons; StyB: Sanderia-type budding; ST: reproduction from parts of stolons/stalks; FSB: typical free-swimming buds/planuloids; MP: motile bud-like tissue particles; POD: podocysts; HL: Helgoland; JP: Japan; FR: France

\begin{tabular}{|lccccccc|}
\hline Species & LB & LBst & StyB & ST & FSB & MP & POD \\
\hline MONO-MODE & & & & & & & \\
FSB-producers & & & & & & & \\
Cassiopea sp. & - & - & - & - & $\checkmark$ & - & - \\
Cephea cephea & - & - & - & - & $\checkmark$ & - & - \\
Mastigias papua & - & - & - & - & $\checkmark$ & - & - \\
Phyllorhiza punctata & - & - & - & - & $\checkmark$ & - & - \\
POD-producers & & & & & & & \\
Lychnorhiza lucerna & - & - & - & - & - & - & $\checkmark$ \\
Rhizostoma pulmo & - & - & - & - & - & - & $\checkmark$ \\
Rhopilema esculentum & - & - & - & - & - & - & $\checkmark$ \\
MULTI-MODE & & & & & & & \\
Aurelia HL $_{\text {Aureliar }}$ & $\checkmark$ & $\checkmark$ & - & $\checkmark$ & - & - & - \\
Aurelia & $\checkmark$ & $\checkmark$ & - & $\checkmark$ & - & $\checkmark$ & $\checkmark$ \\
Sanderia malayensis & - & - & $\checkmark$ & $\checkmark$ & - & $\checkmark$ & - \\
\hline
\end{tabular}



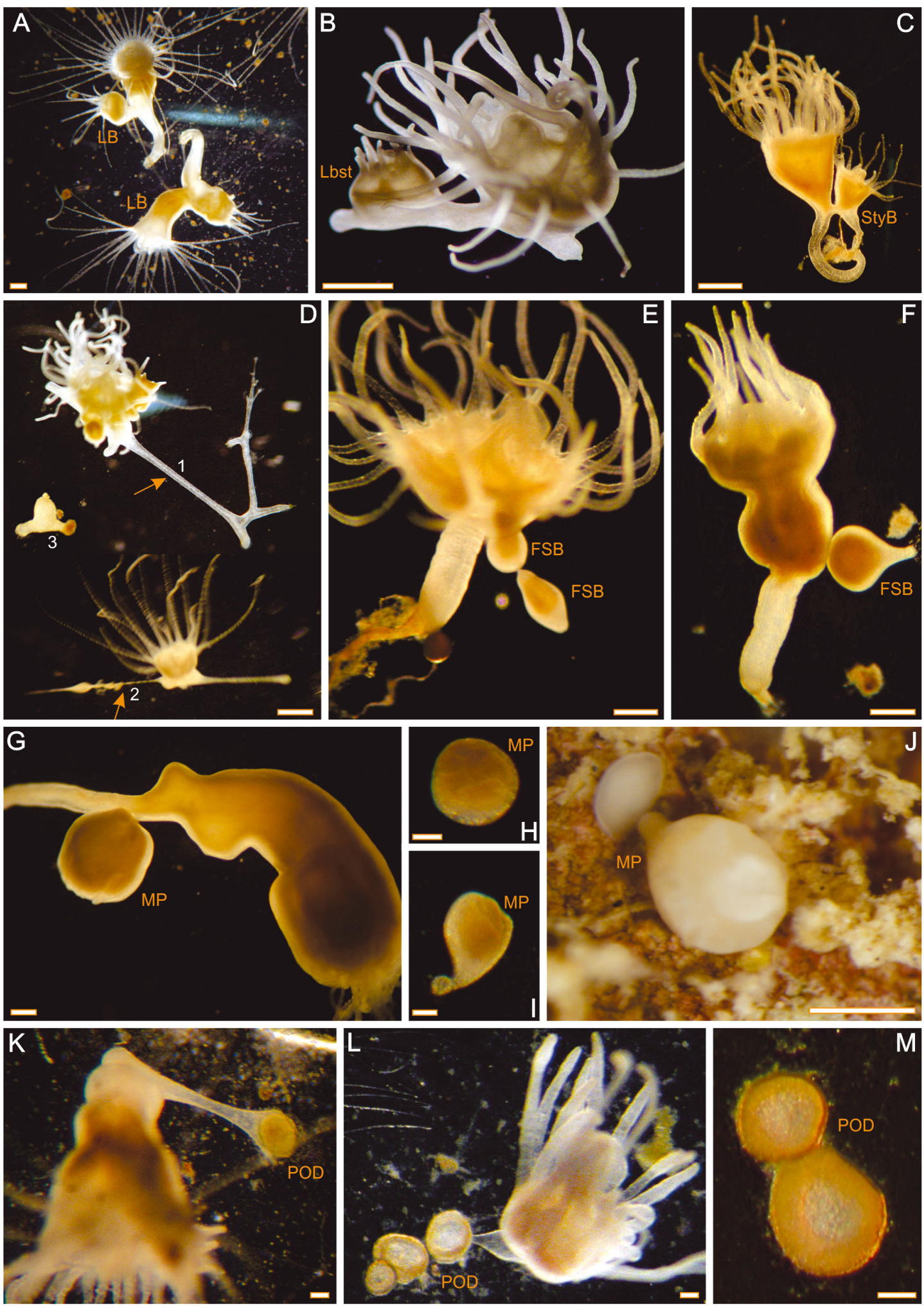

Fig. 1. Different asexual reproduction modes within Scyphozoa. (A) Typical lateral budding (LB; Aurelia sp.); (B) lateral budding by means of stolons (LBst; Aurelia sp.); (C) 'Sanderia-type' budding (StyB; Sanderia malayensis); (D) reproduction from parts of stolons/stalks (Aurelia sp.), successive increasing of tension in the stolon with arrows showing disruption points (1-2) and club-shaped tissue particle remained after disruption (3); (E,F) typical free-swimming buds/planuloids (FSB; E: Cassiopea sp., F: Cephea cephea); (G-J) motile bud-like tissue particles (MP; G: formation of the bud in S. malayensis; H, I, J: development of the motile bud after being released, Aurelia sp.); (K-M) podocysts (POD; K: Aurelia sp., L,M: Lychnorhiza lucerna). Scale bars $=100 \mu \mathrm{m}(\mathrm{A}, \mathrm{B}, \mathrm{C}, \mathrm{K}, \mathrm{L}, \mathrm{M}) ; 200 \mu \mathrm{m}(\mathrm{G}, \mathrm{H}, \mathrm{I}) ; 500 \mu \mathrm{m}(\mathrm{D}, \mathrm{E}, \mathrm{F}, \mathrm{J})$ 
basal region of the scyphistomae or at the attachment area of stolons (or alternatively both). Independent of its origin, POD formation always involved the development of stolons (Fig. 1K,L). These stolons, although identical to other stolons, were not counted as the mode ST.

Survival was high, reaching nearly $100 \%$ in all treatment combinations for all species, indicating an overall tolerance to experimental conditions. The number of asexual reproduction modes displayed by each species varied between 1 and 5 (Table 2). We divided the species into 2 main groups according to the numbers of reproductive modes they exhibited during experiments. The first main group was represented by species displaying only 1 type of reproduction, i.e. the mono-mode species. Among these we defined 2 subgroups: one comprised species producing only FSBs (Cassiopea sp., Cephea cephea, Mastigias papua and Phyllorhiza punctata) and the other included species that only reproduce through PODs (Lychnorhiza lucerna, Rhizostoma pulmo and Rhopilema esculentum) (Table 2, Fig. 1). The second main group of species, i.e. the multi-mode species, comprised Sanderia malayensis and the 3 Aurelia strains. These species reproduced through up to 5 different asexual reproduction modes (Table 2, Fig. 1).
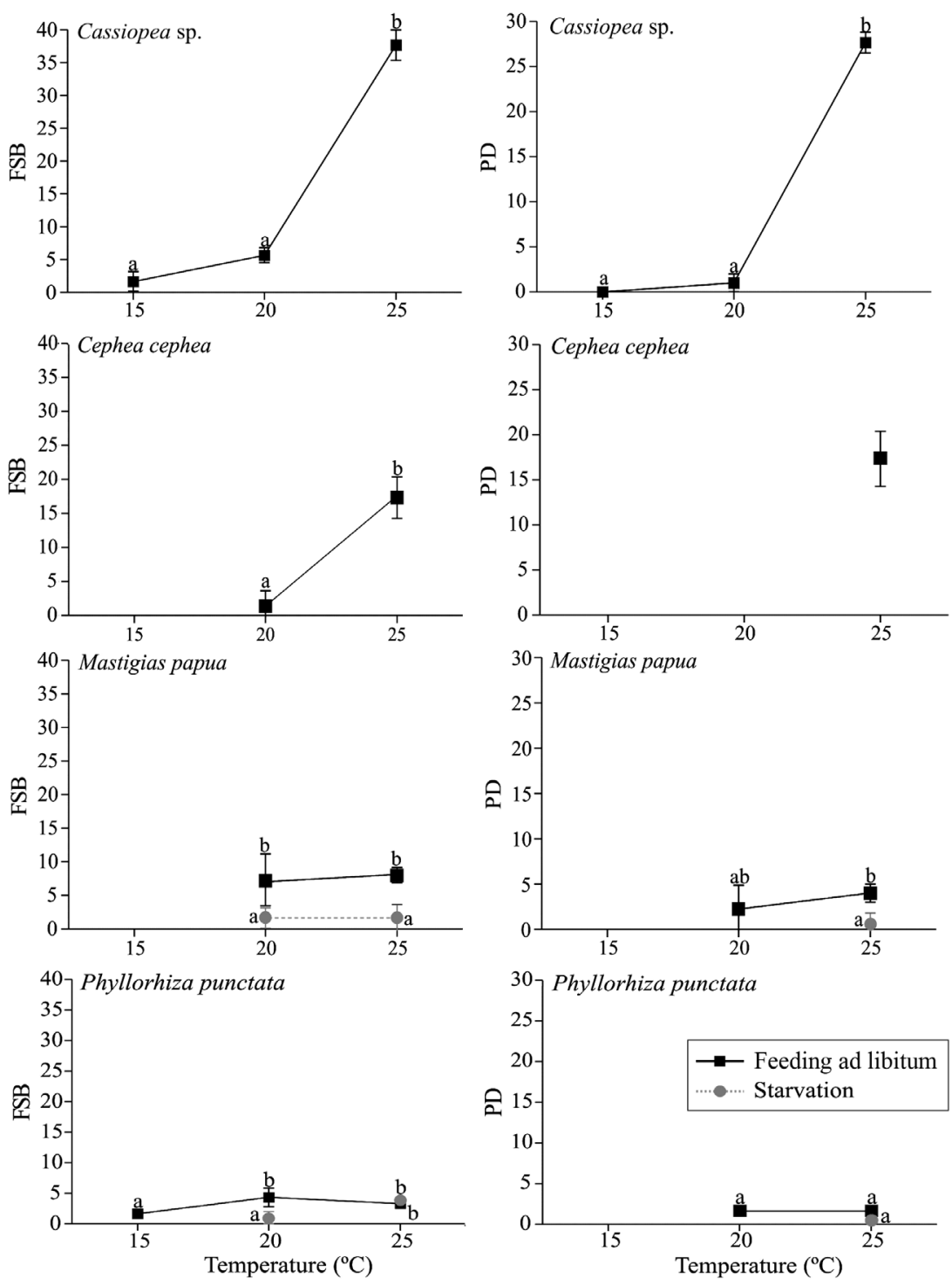

Fig. 2. Effect of temperature and food supply on free-swimming bud/planuloid production (FSB) and polyp density (PD, number of polyps in each experimental unit) of different Scyphozoa after 6 wk. Data are mean numbers of each variable \pm standard deviation. Different letters represent significant differences at $\alpha=0.05$

\section{Overall effects of temperature and food supply on asexual reproduction}

Asexual reproduction rates increased with food availability and warmer temperatures for all species and observed reproduction modes (see Figs. 2-7).

\section{Effects on mono-mode group}

FSB-producers

In general, $\mathrm{Rr}$ increased with food supply and temperature (Fig. 2). No reproduction was observed under starvation conditions at $15^{\circ} \mathrm{C}$. Highest budding rates were reached by fed polyps at the highest temperatures (Cassiopea sp. and C. cephea: $25^{\circ} \mathrm{C}$; M. papua and P. punctata: 20 and $25^{\circ} \mathrm{C}$ ) (Fig. 2). Underlying this basic pattern, the 4 species presented different responses to experimental conditions. No budding was observed under starvation for Cassiopea sp. or C. cephea (Fig. 2). Conversely, $M$. papua and $P$. punctata produced buds during starvation, although at lower rates compared to fed polyps (Fig. 2). In M. papua, budding was observed only at 20 and $25^{\circ} \mathrm{C}$. This species was not able to reproduce at $15^{\circ} \mathrm{C}$ regardless of food availability. In contrast, upon reaching a critical temperature of $20^{\circ} \mathrm{C}$, this species started budding at rates that were elevated by food availability, but not affected by 
higher temperatures (Fig. 2). P. punctata showed the lowest budding rates of this group. However, P. punctata produced a higher number of buds than the other species at $15^{\circ} \mathrm{C}$ and when food was available (Fig. 2).

POD-producers

The highest number of PODs was produced under warmer temperatures while feeding ad libitum (Fig. 3). Excystment was observed only for L. lucerna. No significant effects of the treatments were observed on excystment rates (Fig. 3).

\section{Effects on multi-mode group}

The Aurelia strains and S. malayensis underwent various asexual reproduction modes, including $L B$, LBst, StyB, ST, MP and POD (Table 2, Fig. 1). With the exception of the Cassiopea sp. FSB rate at $25^{\circ} \mathrm{C}$, the multi-mode species presented higher reproduction rates than the mono-mode species. S. malayensis reached the highest production rates (383 new polyps in $6 \mathrm{wk}$ ).

\section{Aurelia $_{\mathrm{FR}}$}

$\mathrm{Rr}$ increased with temperature and food supply (2-way ANOVA; $\mathrm{p}<0.01$ ), and the effects of the interaction between the 2 factors were not significant ( $p$ > 0.05) (Fig. 4A). Rr increased with temperature in fed polyps (Bonferroni's post hoc test; $\mathrm{p}<0.01$ ) (Fig. 4A). The effects on starved polyps were not significant (Bonferroni's post hoc test; p > 0.05) (Fig. 4A). $\mathrm{PD}$ exhibited a similar but sharper response to the studied factors (Fig. 4B).

Forty-eight percent of the new Aurelia FR $_{\text {scy- }}$ phistomae were produced through LB; $32 \%$, by ST; $17 \%$, by LBst; and 3\%, by MPs. The effects of temperature and food supply on the specific asexual modes followed the same pattern described for $\mathrm{Rr}$ (Fig. 4C-H). LB and LBst rates were very low, or even null under starvation, and were enhanced by warmer temperatures (Bonferroni's post hoc test; $\mathrm{p}<0.01$ ) (Fig. $4 \mathrm{C}-\mathrm{F}$ ). The ST rate followed a similar pattern (Mann-Whitney test; $\mathrm{p}<$ 0.05) (Fig. 4G,H). The few MPs observed $(\mathrm{n}=6)$ were produced only by fed polyps at $15^{\circ} \mathrm{C}$. Four PODs were produced by this species, but no excystment was observed.
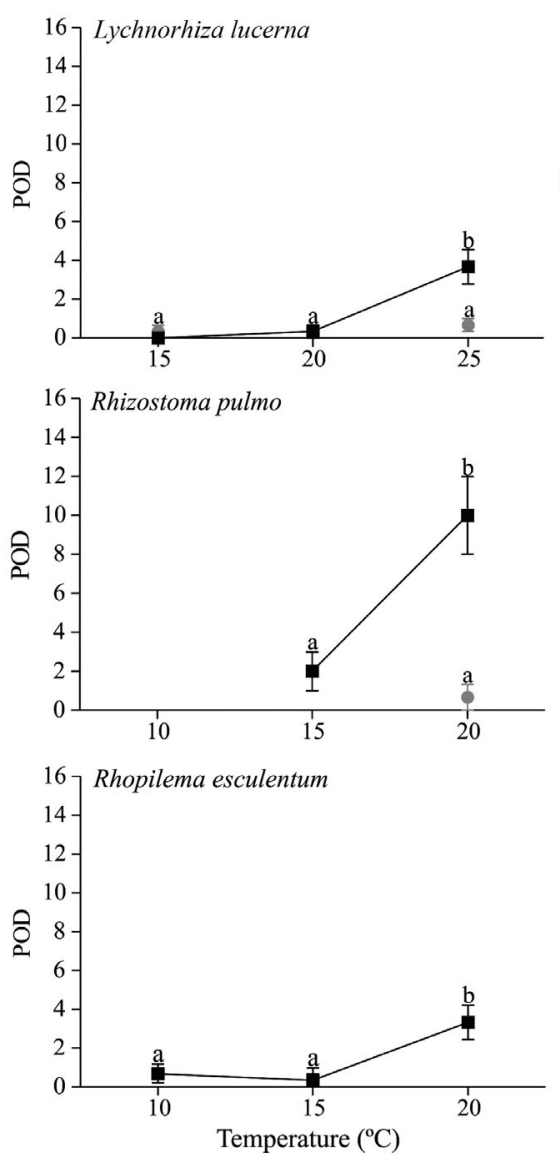
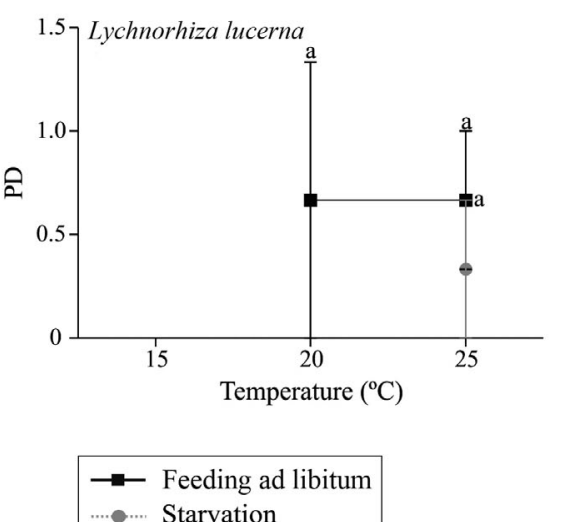

Fig. 3. Effect of temperature and food supply on podocyst production (POD) and polyp density (PD, number of polyps in each experimental unit) of different Scyphozoa after 6 wk. Data are mean numbers of each variable \pm standard deviation. Different letters represent significant differences at $\alpha=0.05$

\section{Aurelia JP}

The effects of temperature and food availability on the $\mathrm{Rr}$ of this species (Fig. 5A) followed the same pattern described for Aurelia $_{\mathrm{FR}}$ (2-way ANOVA; $\mathrm{p}<0.01$ ). Nearly no polyps were developed under starvation (Fig. 5B). Fifty percent of the new Aurelia JP scyphistomae were produced by means of $\mathrm{LB}_{;} 27 \%$, by $\mathrm{ST}_{;} 18 \%$, by LBst; and $5 \%$, by MPs. Temperature and food supply effects on the specific asexual modes followed the same pattern described for Rr (Fig. 5C-H). No LBst were produced by starved polyps or fed polyps at the lowest temperature $\left(15^{\circ} \mathrm{C}\right)$. The LBst rate was enhanced by warmer temperatures (Mann-Whitney test; $\mathrm{p}<0.05$ ) (Fig. 5E). LBst developed into new scyphistomae only at $25^{\circ} \mathrm{C}$ (Fig. 5F). The general pattern observed for ST was the same (Fig. 5G,H) (MannWhitney test; $\mathrm{p}<0.05)$. The few MPs observed $(n=4)$ were produced by 
only fed polyps at $25^{\circ} \mathrm{C}$. All MPs developed into new scyphistomae. No PODs were produced.

\section{Aurelia $_{\mathrm{HL}}$}

The effects of temperature and food availability on $\mathrm{Rr}$ followed the pattern described for the other Aurelia strains (2-way ANOVA; $\mathrm{p}<0.01$ ) (Fig. 6A), but interaction effects were significant $(\mathrm{p}<0.05)$ (Fig. 6A). Rr increased with temperature under both feeding conditions, although reaching higher rates
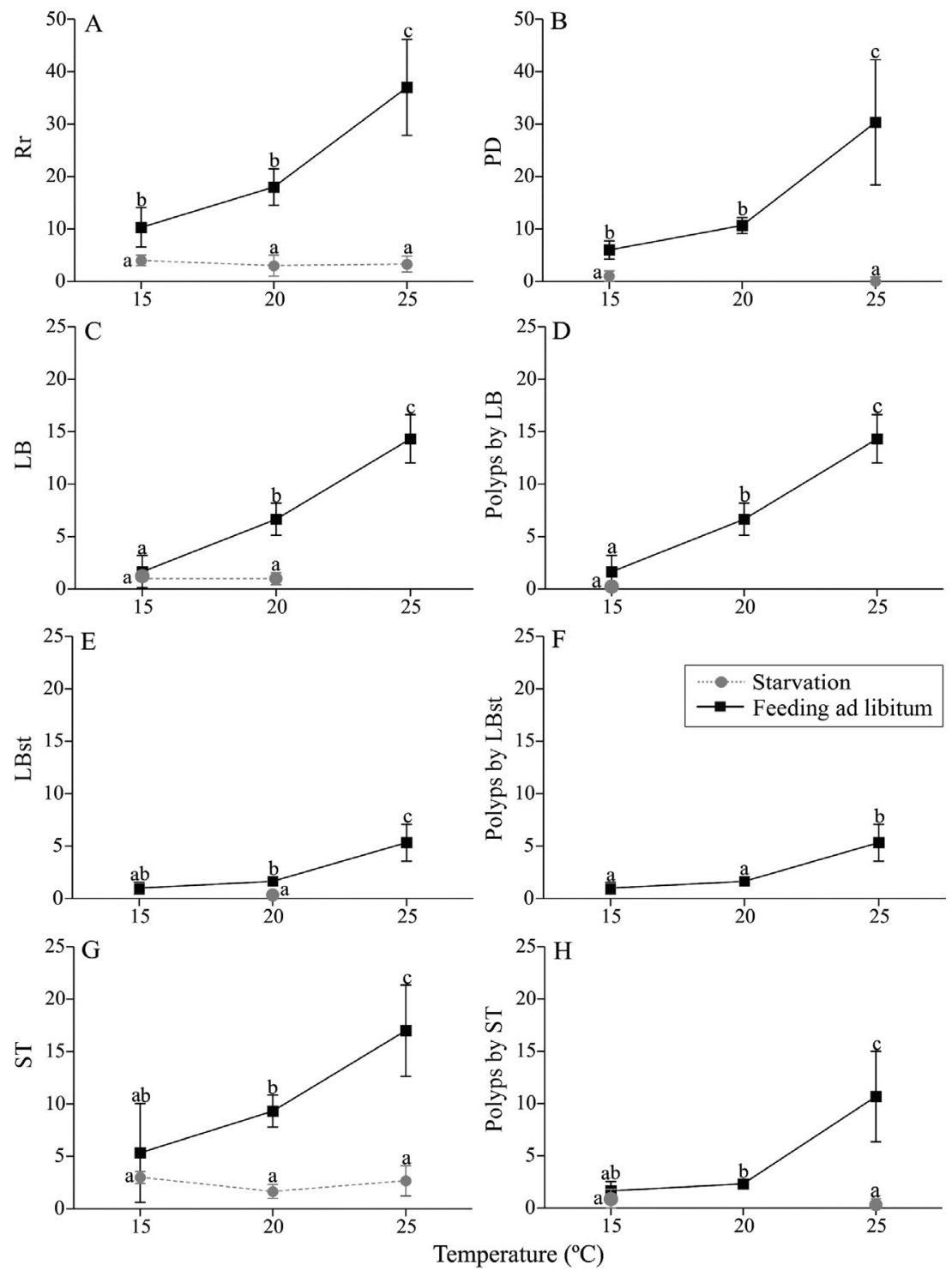

Fig. 4. Effects of temperature and food supply on reproduction rates and polyp density (PD, number of polyps in each experimental unit) of Aurelia ${ }_{\mathrm{FR}}$ Scyphistomae after $6 \mathrm{wk}$. Rr: overall reproduction rates; LB: lateral budding; LBst: lateral budding by means of stolon; ST: reproduction from parts of stolons/stalks. Data are mean numbers of each variable \pm standard deviation. Different letters represent significant differences at $\alpha=0.05$ when food was supplied (Bonferroni's post hoc test; feeding: $\mathrm{p}<0.01$; starving: $\mathrm{p}<0.05$ ) (Fig. 6A). PD under ad libitum feeding displayed the same pattern described for Rr (Bonferroni's post hoc test; $\mathrm{p}<0.05$ ) (Fig. 6B). No effect of temperature on PD was observed under starvation (Bonferroni's post hoc test; p > 0.05) (Fig. 6B). Fifty-five percent of the new Aurelia $a_{\mathrm{HL}}$ scyphistomae were produced by means of LB; \%, by LBst; and $20 \%$, by ST. Neither MPs nor ODs were observed. The effects of temperature and food supply on the specific asexual modes displayed by this species followed the same pattern previously described (Fig. 5C-H).

\section{Sanderia malayensis}

The effects of temperature and food availability on $\mathrm{Rr}$ followed the general pattern previously described for the Aurelia strains (2-way ANOVA; $\mathrm{p}<0.01$ ) (Fig. 7A). The few scyphistomae produced under starvation appeared during the first 2 wk of the experiment. $\mathrm{Rr}$ and $\mathrm{PD}$ were increased by temperature under ad libitum feeding (Bonferroni's post hoc test; $\mathrm{p}<0.01$ ), but their effects were not significant under starvation (Bonferroni's post hoc test; p > 0.05) (Fig. 7A,B). Although reaching different specific rates, the 3 asexual modes utilized by $S$. malayensis followed the same pattern as that described for Rr (Fig. 7C-H).

\section{DISCUSSION}

Our results showed that overall reproduction rates and polyp density increase with higher temperatures and food supply for all species. This suggests that spring to summer is the period in which scyphistomae increase their population size and in which plankton generally shows its annual peak. However, this trend can differ when specific modes of reproduction are considered, such as PODs in Aurelia (see Han \& Uye 2010, Thein et al. 2012). In general, reproduction was very low when no food 

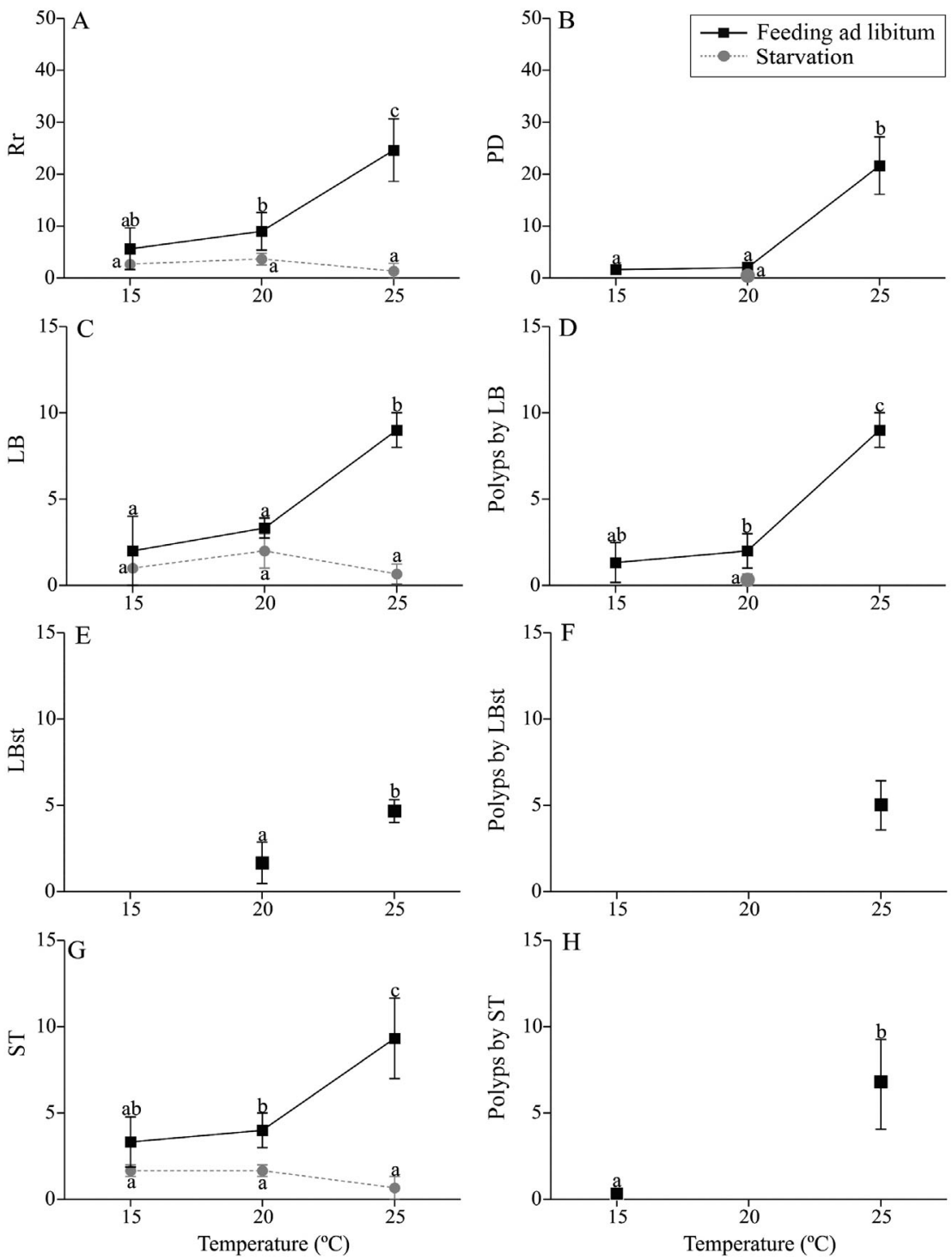

Fig. 5. Effects of temperature and food supply on reproduction rates and polyp density (PD, number of polyps in each experimental unit) of Aurelia ${ }_{\mathrm{JP}}$ Scyphistomae after $6 \mathrm{wk}$. Rr: overall reproduction rates; LB: lateral budding; LBst: lateral budding by means of stolon; ST: reproduction from parts of stolons/stalks. Data are mean numbers of each variable \pm standard deviation. Different letters represent significant differences at $\alpha=0.05$

was available, for all species and temperatures. Starvation appeared to be a common limiting factor for reproduction under all temperature values considered in this study. On the other hand, temperature also affected reproduction rates, but significant effects varied between species. Beyond the reduced metabolic rates, the negative effect of temperature on scyphistoma reproduction was related to the deterioration of tentacles which reduced feeding capability, as we observed for Cassiopea sp. and Cephea cephea at the lowest temperature $\left(15^{\circ} \mathrm{C}\right)$ and for $\mathrm{Au}$ relia at 5 and $10^{\circ} \mathrm{C}$. Therefore, the combined effects of temperature and food supply may synergistically affect scyphistoma reproduction and, subsequently, densities in a positive or negative way.

Although 8 different reproductive modes have been described for Scyphozoa, only Aurelia species and Sanderia malayensis fit into the multimode group. Several examples of other species exhibiting more than 1 mode have been described, such as LB in Catostylus mosaicus, Rhizostoma octopus and R. pulmo (Paspaleff 1938, Pitt 2000, Holst et al. 2007, Straehler-Pohl 2009, Fuentes et al. 2011), LBst and longitudinal fission in $R$. pulmo (S. Franke pers. obs.) and Cassiopea andromeda (Gohar \& Eisawy 1960, Hofmann et al. 1978) and MP in C. cephea (A. Schiariti pers. obs.). However, these observations must be considered exceptional cases with negligible contributions to polyp density.

The species displaying multi-mode strategies possessed the highest reproduction rates. Aurelia and S. malayensis achieved substantially higher reproduction rates than the species reproducing by mono-mode strategies. Among the latter species, the FSB-producers presented higher rates than the POD-producers. Even though lacking a description of specific reproduction modes, Purcell et al. (2012) observed the same relationship between reproduction rates and reproductive strategies. These authors reported the highest 'budding' rates reached for the multi-mode $A$. aurita, the lowest for the POD-producer $R$. pulmo, with intermediate values reached by the FSBproducer Cotylorhiza tuberculata (see Kikinger 1992 for reproduction strategy of $C$. tuberculata). Thein et al. (2013) also reported higher reproduction rates of Aurelia compared to the POD-producers Chrysaora pacifica and Cyanea nozakii.

Yet, what matters about reproduction rates is not the number of available modes a species can display but how rapidly these modes can develop functional polyps. Aurelia and S. malayensis can display most of the asexual reproduction modes described for the Scyphozoa (Adler \& Jarms 2009, present study). 

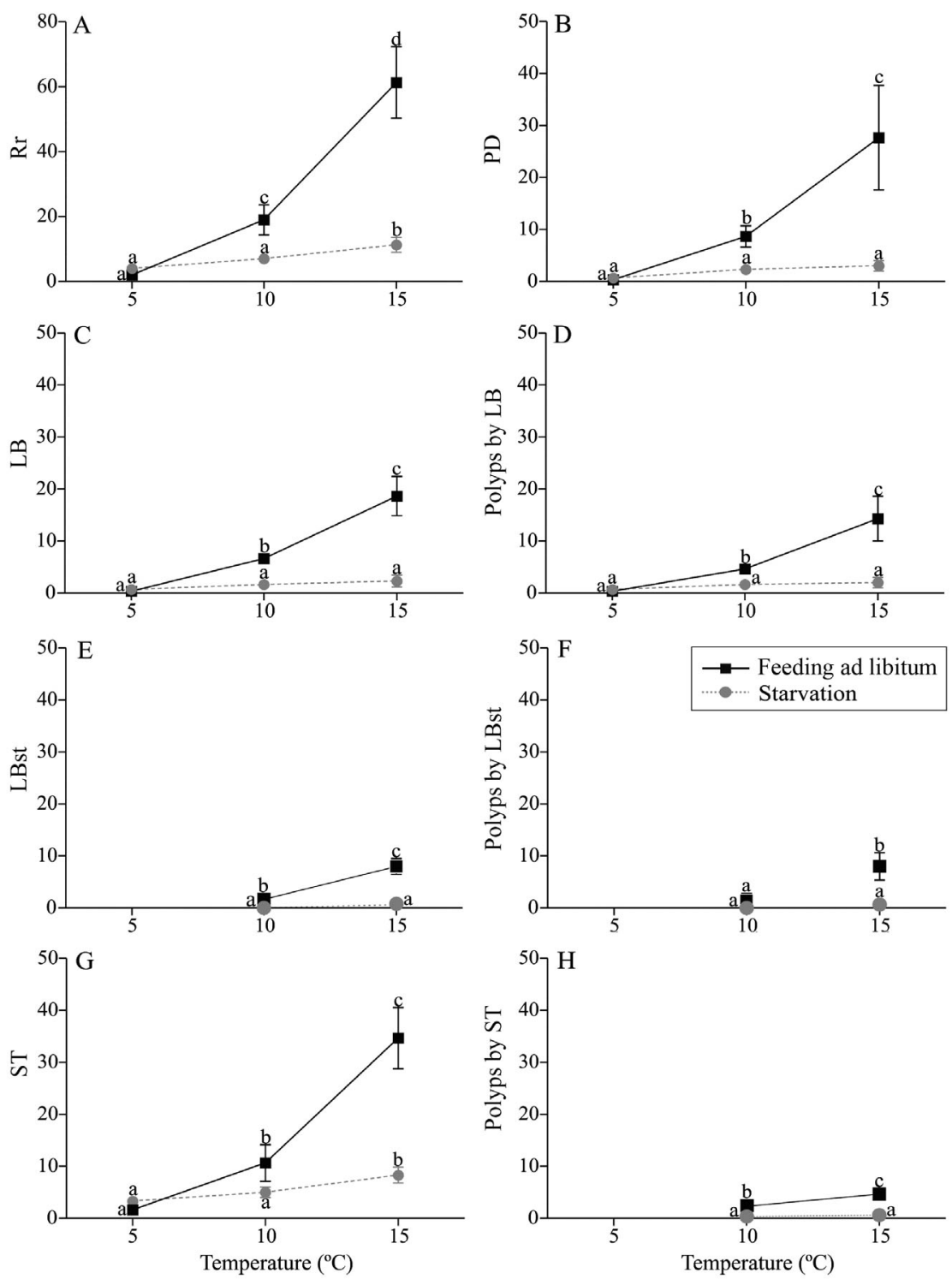

Fig. 6. Effects of temperature and food supply on reproduction rates and polyp density (PD, number of polyps in each experimental unit) of Aurelia ${ }_{\mathrm{HL}}$ scyphistomae after $6 \mathrm{wk}$. Rr: overall reproduction rates; LB: lateral budding; LBst: lateral budding by means of stolon; ST: reproduction from parts of stolons/stalks. Data are mean numbers of each variable \pm standard deviation. Different letters represent significant differences at $\alpha=0.05$

However, they propagate almost exclusively (95 to $100 \%$ ) through LB (or StyB), LBst and ST when food is available. The utilization of these modes (mostly LB) allows a very rapid colonization of available

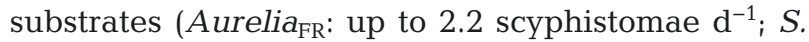
malayensis: up to 4.5 scyphistomae $\mathrm{d}^{-1}$ ). The formation of a new scyphistoma takes between 3 and $5 \mathrm{~d}$ from the first signs of the bud to detachment of the new scyphistoma. The new bud develops its tentacles and starts feeding before detachment, becoming a double-headed polyp with elevated feeding rates, allowing increased energy storage for reproductive and somatic growth. The same pattern has been described for A. aurita s.l. by Han \& Uye (2010).

These 'speedy' reproduction modes are present in multi-mode species such as $A$. aurita, A. limbata, A. labiata and $S$. malayensis (Adler \& Jarms 2009 and references therein, present study). Some of these modes have also been described for other species like Phacellophora camtschatica, Chrysaora hysoscella, C. quinquecirrha, $C y$ anea capillata, C. lamarkii, Catostylus mosaicus, $R$. pulmo and $R$. octopus (Lambert 1935, Gröndahl \& Hernroth 1987, Pitt 2000, Widmer 2006, Holst et al. 2007, Adler \& Jarms 2009 and references therein, Straehler-Pohl 2009, Fuentes et al. 2011, Holst 2012). However, as stated above, these reports describe exceptional cases that contribute very little in terms of the population's reproductive output.

In addition to their high $\mathrm{Rr}$, the formation of polyps by means of LB, LBst, or StyB produces scyphistomae right beside the mother polyp, allowing rapid colonization of available substrates when conditions are optimal. On the other hand, Han \& Uye (2010) and Thein et al. (2012) observed that $A$. aurita encyst only under conditions of starvation or food scarcity. Besides, Aurelia start developing MPs once a certain threshold in density is achieved (the carrying capacity of the population) (Melica 2013). In turn, Aurelia scyphistomae can detach from the substrate and drift with currents in response to overcrowding (Melica 2013). Thus, the multi-mode reproduction strategy allows Aurelia to colonize the available substrate rapidly when conditions are favourable, to encyst and withstand starvation and other adverse conditions and to develop motile buds or detach in order to facilitate dispersion and avoid the negative effects of inter- or intraspecific competition for space and food. The potential capability to switch its reproductive strategy in response to environmental clues gives Aurelia high adaptability. Considering these features, in addition to the wide tolerance of Aurelia scyphistomae (and 

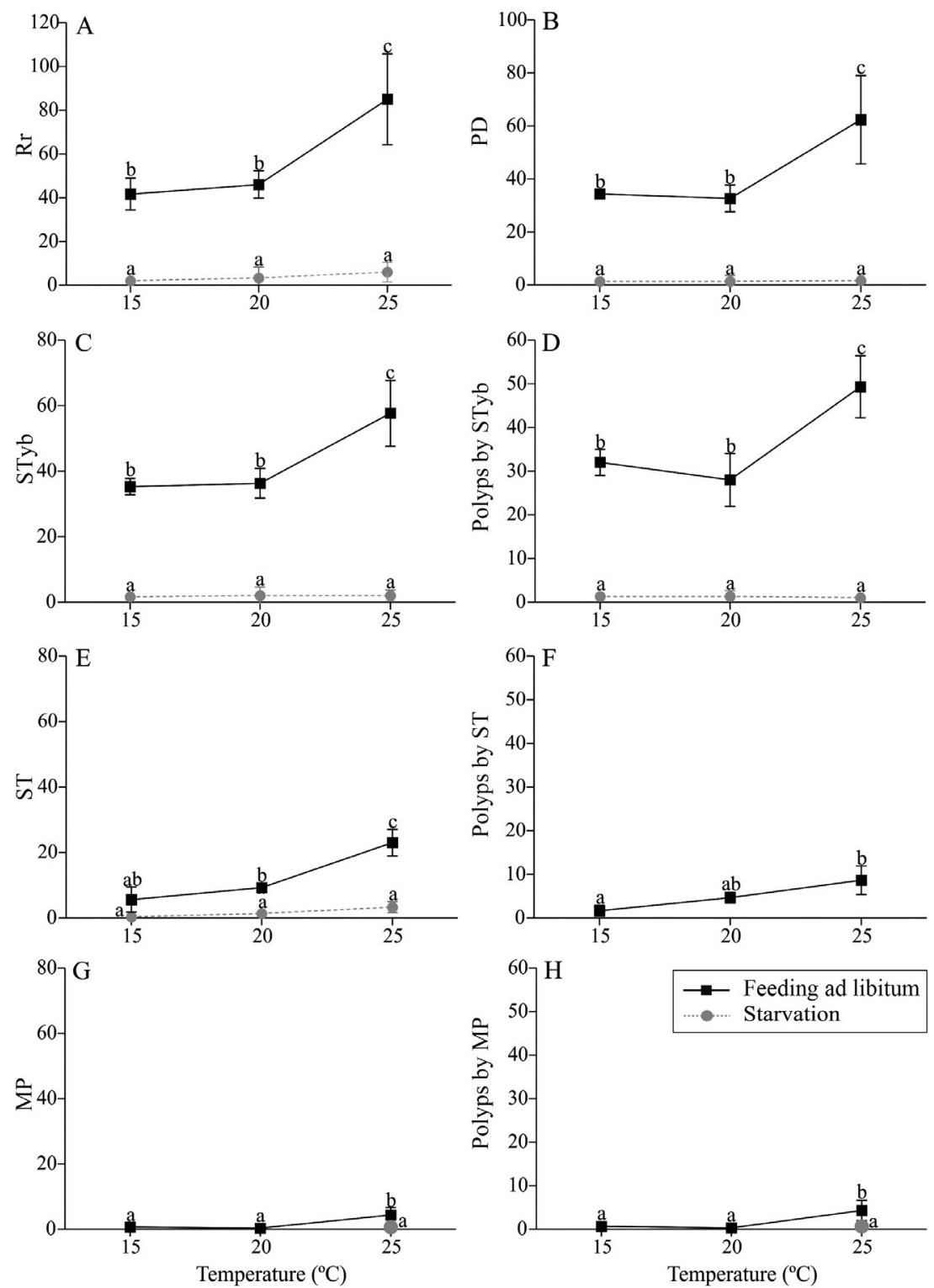

Fig. 7. Effects of temperature and food supply on reproduction rates and polyp density (PD, number of polyps in each experimental unit) of Sanderia malayensis scyphistomae after 6 wk. Rr: overall reproduction rates; StyB: 'Sanderiatype' budding; ST: reproduction from parts of stolons/stalks; MP: motile budlike tissue particles. Data are mean numbers of each variable \pm standard deviation. Different letters represent significant differences at $\alpha=0.05$
As for Aurelia, a considerable propagation capability is achieved, for the most part, through StyB and ST. Again, polyps colonize the available substrate, producing many non-motile particles in short periods of time. $S$. malayensis is also capable of producing motile particles and detaching from the substrate in order to move from one place to another (Adler \& Jarms 2009, present study, A. Schiariti pers. obs.). Furthermore, it can also form planuloids from tentacle tips/ pieces as another mode of producing new polyps and facilitating dispersion (Adler \& Jarms 2009). Up to now, the factors that favour the production of these motile products have remained unidentified. However, despite such high propagation capabilities, there has only been 1 report of a $S$. malayensis bloom (Xian et al. 2005-although the image presented in the paper does not resemble Sanderia). How can one explain that one species commonly blooms and the other does not? The answer may lie in a phylogenetic signal (Dawson \& Hamner 2009, Hamner \& Dawson 2009), as well as in the factors that regulate strobilation rates and ephyra survival. Although we have maintained cultures of these species for several years in the 3 laboratories, we have no clues as to why strobilation is commonly observed in Aurelia but is very rare in S. malayensis. Furthermore, Aurelia species produce ephyrae through polidisc strobilation, while Sanderia utilizes monodisc strobilation (e.g. Uchida \& Sugiura 1978, Lucas 2001). Thus, if we double the number of Sanderia scyphistomae we will, at medusae) to environmental parameters (Lucas 2001, Lucas et al. 2012), it is not surprising that the species/ lineages of Aurelia are cosmopolitan and exhibit the most frequent bloom events.

S. malayensis presents, in general, a reproduction strategy similar to that of Aurelia strains, with the exception of PODs. This species exhibits the highest reproduction rates ever reported for a scyphistoma under laboratory conditions (Adler \& Jarms 2009, G. Jarms, A. C. Morandini \& A. Schiariti unpubl. data). most, double the number of medusae, but, in the case of Aurelia, if we double the number of scyphistomae we might increase the number of medusae 10- to 20-fold.

In contrast to Aurelia, POD formation has not been observed for S. malayensis (Uchida \& Sugiura 1978, Adler \& Jarms 2009, present study). Moreover, this species is sensitive to starvation, with very low or negligible reproduction rates when food is not available. Therefore, reproduction rates might be slow 
during low-food periods, and, lacking cysts, the population might decrease in size. However, this is only speculation, and further experiments should be performed to explain which factors control the density of Sanderia scyphistomae, their strobilation rates and the survival and growth of medusa stages.

PODs can survive extreme conditions, providing protection against chemical attacks (Blanquet 1972), starvation periods ( $>3 \mathrm{yr}, A$. aurita, Thein et al. 2012; 6 yr, Nemopilema nomurai, Kawahara et al. 2013) and predation (Cargo \& Schultz 1966, Hernroth \& Gröndahl 1985). Therefore, it is likely that the capability to encyst has evolved in order to withstand conditions in which polyps would not otherwise survive (Arai 2009). The earliest literature speculated that PODs were produced under stress to provide protection against adverse conditions. Below some food threshold, A. aurita scyphistomae may shift the allocation of nutrition from bud formation to POD production (Thein et al. 2012). However, contrasting results have been provided for other species where encystment only occurs when food is available and POD production is accelerated by enhanced food supply. Interestingly, the species which require food to produce PODs are those we have classified in this work as the POD-producers adopting a mono-mode strategy. The production of PODs increases with food supply for the rhizostomes L. lucerna, $R$. pulmo, $R$. esculentum, Nemopilema nomurai and Stomolophus meleagris (Jiang et al. 1993, Lu et al. 1997, Schiariti et al. 2008, González Valdovinos 2010, Purcell et al. 2012, Kawahara et al. 2013, present study) and for the semaeostomes Chrysaora pacifica, C. quinquecirrha and Cyanea nozakii (Littleford 1939, Thein et al. 2013). Therefore, food availability appears to be a key factor triggering POD production. While in the multi-mode species, starvation and food scarcity promote encystment, in the mono-mode POD-producers, food is required for reproduction, as it is for budding in multi-mode species and FSB-producers.

The utilization of cysts to withstand adverse conditions or as a reproductive mode appears to be related to the capability of the species to form polyps by another different and faster alternative, like LB. In contrast to the multi-mode Aurelia, POD production by mono-mode species requires a certain level of energy supply. Above this threshold, POD production rates increase with temperature and food availability, as observed in our present work and in previous studies (e.g. Thein et al. 2013). Even in Aurelia, once encystment has been triggered, POD production rates appear to increase with temperature (Thein et al. 2012, present study).
As usual some exceptions can be found, e.g. the sea nettle $C$. quinquecirrha encysts when temperatures fall below 2 to $4^{\circ} \mathrm{C}$ (Cargo \& Schultz 1967). Nevertheless, differences in experimental conditions among studies and other possible factors may have led to controversial results. Other factors have been reported to induce POD production in addition to energy supply. Bacterial fouling has been mentioned as one of the stressful conditions triggering encystment (Cargo \& Schultz 1966, Blanquet 1972). Schiariti et al. (2008) attributed the high POD production rate observed for L. lucerna to a combination of conspicuous bacterial fouling in culture dishes and the experimental temperature and feeding conditions. However, observations of several POD-producers (e.g. L. lucerna, C. lactea, C. achylos, C. colorata, C. fuscescens) from our laboratory cultures indicate that unattached scyphistomae are not capable of producing PODs. As described above, the production of PODs requires the formation and attachment of a stolon. Hence, special substrate properties, and probably the presence of bacterial fouling, influence the attachment rate of stolons (Schmahl 1985). Therefore, differences in the substrate conditions utilized in the different experiments may have influenced podocyst production rates through their influence on stolon attachment.

\section{CONCLUSIONS}

Our results confirm some general trends discussed in the literature, but here we have provided experimental data on several scyphozoan groups to corroborate speculation in the literature. The main results of our experiments show that with increasing temperature and food supply the rate of asexual reproduction of several species is increased. These conditions are major symptoms of the deterioration in marine environments caused by several anthropogenic actions that favour jellyfish (viz. Purcell et al. 2007, Richardson et al. 2009). Our data clearly show that at higher temperatures and levels of available food polyp density increases. If polyp density increases, the magnitude of blooms is augmented considerably. However, the potential for a species to regulate its polyp density depends on the capability of adapting its reproductive strategy in response to the environmental conditions.

Beyond the recruitment rate of settled planulae, polyp density is exclusively dependent on asexual reproduction rates. Thus, those species capable of producing non-motile particles (LB, LBst, ST) would 
exhibit the highest reproduction rates, followed by those producing FSBs and PODs. In the latter case, not only the slowest reproduction rates, but also the need for 2 sets of environmental stimuli in order to produce new polyps (one for encystment, another for excystment), makes this mode of reproduction the slowest of those observed to be utilized for propagation.

On the other hand, species capable of producing podocysts can reduce mortality rates through encystment. Although it is true that this also reduces actual polyp density, these populations have the potential to re-grow once favourable conditions have returned, enhancing their blooming potential as described by Kawahara et al. (2013). Alternatively, the species that produce motile particles can potentially avoid or reduce competition for space and food by reaching new settlement sites. At the same time, we observed that the FSB-producers are among this group, which, as mono-mode species, have no other alternatives for propagation. These species are mostly tropical and more sensitive to cold temperatures. Therefore, scyphistomae that are not capable of encystment are found throughout the mid- to late summer but are completely absent during winter and early spring $(C$. xamachana; Fitt \& Costley 1998). In these cases, not only scyphistoma density but also the continuity of the species strongly depends on the success of sexual reproduction and its pelagic stages.

Therefore, the ability of multi-mode species to switch their reproductive strategies in response to environmental conditions increases the fitness of these species and enhances their potential to bloom.

Acknowledgements. We thank Valentina Melica for the photograph in Fig. 1J and Jack Costello for his helpful comments. This work was funded by INIDEP and Grants CONICET PIP 201300615 and PICT 2013-1713 (Argentina), and Grants 2010/50174-7, 2011/50242-5 and 2013/05510-4, São Paulo Research Foundation (FAPESP), CNPq 301039/2013-5 and CAPES PROEX (Brasil). This study is a contribution of NP-BioMar, USP. This is INIDEP Contribution No. 1859.

\section{LITERATURE CITED}

Adler L, Jarms G (2009) New insights into reproductive traits of scyphozoans: special methods of propagation in Sanderia malayensis GOETTE, 1886 (Pelagiidae, Semaeostomeae) enable establishing a new classification of asexual reproduction in the class Scyphozoa. Mar Biol 156:1411-1420

> Arai MN (2009) The potential importance of podocysts to the formation of scyphozoan blooms: a review. Hydrobiologia 616:241-246

Blanquet RS (1972) Structural and chemical aspects of the podocyst cuticle of the scyphozoan medusa, Chrysaora quinquecirrha. Biol Bull 142:1-10

> Cargo DG, Schultz LP (1966) Notes on the biology of the sea nettle, Chrysaora quinquecirrha, in Chesapeake Bay. Chesap Sci 7:95-100

> Cargo DG, Schultz LP (1967) Further observations on the biology of the sea nettle, Chrysaora quinquecirrha, and jellyfishes in Chesapeake Bay. Chesap Sci 8:209-220

CIESM (The Mediterranean Science Commission) (2001) Gelatinous zooplankton outbreaks: theory and practice. CIESM Workshop Series 14, CIESM, Monaco

Dawson MN, Hamner WM (2009) A character-based analysis of the evolution of jellyfish blooms: adaptation and exaptation. Hydrobiologia 616:193-215

Fitt WK, Costley K (1998) The role of temperature in survival of the polyp stage of the tropical rhizostome jellyfish Cassiopea xamachana. J Exp Mar Biol Ecol 222:79-91

$>$ Fuentes V, Straehler-Pohl I, Atienza D, Franco I and others (2011) Life cycle of the jellyfish Rhizostoma pulmo (Scyphozoa: Rhizostomeae) and its distribution, seasonality and inter-annual variability along the Catalan coast and the Mar Menor (Spain, NW Mediterranean). Mar Biol 158:2247-2266

Gohar HAF, Eisawy AM (1960) The development of Cassiopea andromeda (Scyphomedusae). Publ Mar Biol Sta Ghardaqa (Red Sea) 11:147-190

González Valdovinos MI (2010) Alimentación y desarrollo en la fase pólipo de la medusa bola de cañón Stomolophus meleagris L. Agassiz, 1860 (Scyphozoa, Rhizostomida). MSc dissertation, Universidad Autónoma de Baja California Sur, La Paz

Gröndahl F, Hernroth L (1987) Release and growth of Cyanea capillata (L.) ephyrae in the Gullmar Fjord, western Sweden. J Exp Mar Biol Ecol 106:91-101

Hamner PP, Dawson MN (2009) A review and synthesis on the systematics and evolution of jellyfish blooms: advantageous aggregations and adaptive assemblages. Hydrobiologia 616:161-191

> Han CH, Uye SI (2010) Combined effects of food supply and temperature on asexual reproduction and somatic growth of polyps of the common jellyfish Aurelia aurita s.l. Plankton Benthos Res 5:98-105

> Hernroth L, Gröndahl F (1985) On the biology of Aurelia aurita (L.). 3. Predation by Coryphella verrucosa (Gastropoda, Opistobranchia). A major factor regulating the development of Aurelia populations in the Gullmar Fjords, western Sweden. Ophelia 24:37-45

- Hofmann DK, Neumann R, Henne K (1978) Strobilation, budding and initiation of scyphistoma morphogenesis in the rhizostome Cassiopea andromeda (Cnidaria: Scyphozoa). Mar Biol 47:161-176

> Holst S (2012) Morphology and development of benthic and pelagic life stages of North Sea jellyfish (Scyphozoa, Cnidaria) with special emphasis on the identification of ephyra stages. Mar Biol 159:2707-2722

> Holst S, Sötje I, Tiemann H, Jarms G (2007) Life cycle of the rhizostome jellyfish Rhizostoma octopus (L.) (Scyphozoa, Rhizostomeae), with studies on cnidocysts and statoliths. Mar Biol 151:1695-1710

Jiang S, Lu N, Chen J (1993) Effect of temperature, salinity and light on the germination of the podocyst of Rhopilema esculenta. Fish Sci 12:1-4 (Japanese with English abstract)

> Kawahara M, Ohtsu K, Uye SI (2013) Bloom or non-bloom in the giant jellyfish Nemopilema nomurai (Scyphozoa: Rhizostomeae): roles of dormant podocysts. J Plankton 
Res 35:213-217

Kikinger R (1992) Cotylorhiza tuberculata (Cnidaria: Scyphozoa) - Life history of a stationary population. Mar Ecol 13:333-362

Lambert FJ (1935) Jellyfish. The difficulties of the study of their life history and other problems. Essex Naturalist 25:70-86

Littleford RA (1939) The life cycle of Dactylometra quinquecirrha, L. Agassiz in the Chesapeake Bay. Biol Bull 77:368-381

Lu N, Jiang L, Chen J (1997) Effect of temperature, salinity and light on the podocyst generation of Rhopilema esculenta Kishnouye. Fish Sci 16:3-8

Lucas CH (2001) Reproduction and life history strategies of the common jellyfish, Aurelia aurita, in relation to its ambient environment. Hydrobiologia 451:229-246

- Lucas CH, Graham WM, Widmer C (2012) Jellyfish life histories: role of polyps in forming and maintaining scyphomedusa populations. Adv Mar Biol 63:133-196

Melica V (2013) Influence of substrate availability on the population growth and on asexual reproduction strategies of Aurelia sp. polyps. MSc dissertation, University of Trieste

Paspaleff BW (1938) Über die Entwicklung von Rhizostoma pulmo Agass. Arbeiten aus der Biologischen Meeresstation am Schwarzen Meer in Varna 7:1-25

Pitt KA (2000) Life history and settlement preferences of the edible jellyfish Catostylus mosaicus (Scyphozoa: Rhizostomeae). Mar Biol 136:269-279

Purcell JE, Uye S, Lo WT (2007) Anthropogenic causes of jellyfish blooms and their direct consequences for humans: a review. Mar Ecol Prog Ser 350:153-174

Purcell JE, Atienza D, Fuentes V, Olariaga A, Tilves U, Cola-

Submitted: November 20, 2013; Accepted: March 24, 2014 han C, Gili JM (2012) Temperature effects on asexual reproduction rates of scyphozoan species from the northwest Mediterranean Sea. Hydrobiologia 690:169-180

- Richardson AJ, Bakun A, Hays GC, Gibbons MJ (2009) The jellyfish joyride: causes, consequences and management responses to a more gelatinous future. Trends Ecol Evol 24:312-322

Schiariti A, Kawahara M, Uye Si, Mianzan HW (2008) Life cycle of the jellyfish Lychnorhiza lucerna (Scyphozoa: Rhizostomeae). Mar Biol 156:1-12

Schmahl G (1985) Bacterially induced stolon settlement in the scyphopolyp of Aurelia aurita (Cnidaria, Scyphozoa). Helgol Mar Res 39:33-42

Straehler-Pohl I (2009) Die Phylogenie der Rhopaliophora (Scyphozoa und Cubozoa) und die Paraphylie der 'Rhizostomeae'. PhD thesis, Universität Hamburg

> Thein H, Ikeda H, Uye SI (2012) The potential role of podocysts in perpetuation of the common jellyfish Aurelia aurita s.l. (Cnidaria: Scyphozoa) in anthropogenically perturbed coastal waters. Hydrobiologia 690:157-167

Thein H, Ikeda H, Uye SI (2013) Ecophysiological characteristics of podocysts in Chrysaora pacifica (Goette) and Cyanea nozakii Kishinouye (Cnidaria: Scyphozoa: Semaeostomeae): effects of environmental factors on their production, dormancy and excystment. J Exp Mar Biol Ecol 446:151-158

Uchida T, Sugiura Y (1978) On the polyp of the Scyphomedusa, Sanderia malayensis and its reproduction. J Fac Sci Hokkaido Univ 21:279-287

Widmer CL (2006) Life cycle of Phacellophora camtschatica (Cnidaria: Scyphozoa). Invertebr Biol 125:83-90

Xian W, Kang B, Liu R (2005) Jellyfish blooms in the Yangtze Estuary. Science 307:41

Proofs received from author(s): May 26, 2014 